\title{
Effect of Turmeric on the Growth of Pathogenic and Probiotic Bacteria
}

\author{
P. S. Priyanka ${ }^{1 *}$ and Betty Rani Isaac ${ }^{2}$ \\ 'Student, M.Sc Food Science and Nutrition, Department of Home Science, St. Teresa's College, \\ Ernakulam, Kerala, India; priyankapsasikumar@gmail.com \\ ${ }^{2}$ Associate Professor and Head of the Department, Department of Home Science, \\ St. Teresa's College, Ernakulam. Kerala, India; bettyranijose@yahoo.com
}

\begin{abstract}
The study has been undertaken to explore the significant antibacterial activity exhibited by extract of Turmeric the dried rhizome of Cucurma longa, an herbaceous plant, and native to tropical South East Asia. It is titled as "Golden spice" as well as "spice of life" due to its cardinal role in ameliorating grievous diseases. This study also explores the effect on growth of the beneficial probiotic bacteria which keeps human gut healthy. The pathogenic bacterial strains included gram positive Bacillus cereus and Staphylococcus aureus, gram negative Escherichia coli and Salmonella typhimurium. The probiotic bacterial strains selected for the study included gram positive Lactobacillus and Bifidobacterium. Disc diffusion method was opted to study the zone of inhibition exhibited by these spice extracts on the selected bacterial strains. Turmeric was effective against E. coli, Staphylococcus aureus and Bacillus cereus. The pioneer study conducted based on the sensitivity of probiotic bacteria on the spice extract revealed that the growth of these beneficial bacteria is not inhibited. Thus the study brings out the significance of spices in maintaining the health and longevity.
\end{abstract}

Keywords: Antibacterial Activity, Disc Diffusion Method, Pathogenic, Probiotic, Turmeric

\section{Introduction}

Spices are one among the edible category of plants. A spice can be a dried seed, fruit, root, bark, or vegetable used for flavoring, coloring or preserving food. They are distinguished from herbs, which are parts of leafy green plants used for flavoring or as a garnish. In addition to the above benefits, many of the spices possess antimicrobial, medicinal, antibiotic, antifungal properties. Spices are considered to be inevitable in religious rituals and are the most important forms of natural foods used in indigenous system of medicine as natural healers since ancient times.

Turmeric is an herbaceous perennial plant with a thick underground rhizome giving rise to primary and secondary rhizomes called fingers. Traditionally, turmeric has been used in topical applications to heal wounds. It purifies the blood and subdues accumulated gasses. It relieves pain, cures jaundice, inflammation, skin diseases, itching and diabetes. It has also been used internally for liver and digestive complaints, menstrual insufficiency and cramping. Recent studies have unveiled the properties of turmeric to cure Alzheimer's, cancer, hyperlipedemia, osteoarthritis and irritable bowel syndrome. Turmeric (Curcuma longa) has also been found to be an efficient antioxidant/DNA-protectant/antimutagen activity [1-3].

Spices contain an impressive list of plant-derived chemical compounds that are known to have disease preventing and health promoting properties. They have been in use since ancient times for their anti-inflammatory, carminative, anti-flatulent properties. 
Many spices contain substances known to inhibit the growth of microorganisms. The interest in using spices or their constituents as food preservatives is founded on a wide belief that any natural substance is less harmful than a synthetic one. Spice ingredients with antimicrobial activity include aldehydes, organic acids, phenols and essential oils. The antimicrobial action can be discussed under three main types, antimicrobial activity over bacteria, yeast and fungus.

Therefore the present study was undertaken to bring out the antibacterial activity of Turmeric (Curcuma longa L.) on both pathogenic and probiotic strains of microorganisms. The identification of antibacterial activity of the spice against the pathogenic bacteria explores the relevance of using them in pharmacology as well as in food industry as bio - preservators. A new aspect is also being studied, that "whether the use of these spices inhibits the growth of the beneficial probiotic bacteria of the gut".

\section{Materials and Method}

\subsection{Selection of Sample}

Turmeric is one among the major spices produced in Kerala. Both the fresh and dry sample of the spice was collected for the study and was procured from Ernakulam.

\subsection{Selection of Bacterial Test Strains}

Effect of the spice on growth of bacteria was studied using two different bacterial strains namely pathogenic and probiotic. The details of the bacterial strains selected for the study are given below.

\subsubsection{Selection of Pathogenic Bacteria}

Pathogenic bacteria are those bacteria which can cause infection to humans. They cause infections such as tuberculosis, tetanus, typhoid fever, diphtheria, syphilis, and leprosy. The activity of selected spice to inhibit the growth of pathogenic bacteria was studied on four different strains namely Bacillus cereus, Staphylococcus aureus, Escherichia coli and Salmonella typhimurium.

\subsubsection{Selection of Probiotic Bacteria}

Probiotics are naturally found live microorganisms that are good for health, especially the digestive system. They are often called "good" or "helpful" bacteria because they help to keep our gut healthy. An effort was undertaken to find out, whether the extract of selected spice have a negative impact on the helpful probiotic bacteria. Therefore the study included the sensitivity test of the beneficial bacteria towards the spice extract.

\subsection{Microbial Analysis}

\subsubsection{Preparation of the Sample of Spices}

The fresh sample of turmeric was first de-skinned and was further washed and cleaned thoroughly with distilled water.

\subsubsection{Extraction of Fresh and Dry Spice Samples}

The extraction of spice was done with both aqueous and methanolic medium.

\subsubsection{Aqueous Extraction of Fresh Sample}

The cleaned sample was pulverized with sterile motor and pestle. The extraction was done twice with distilled water $(2: 20 \mathrm{w} / \mathrm{v})$ and then the extract was sieved through sterile fine mesh to a $50 \mathrm{ml}$ beaker to make $100 \%$ extract. The beakers were covered with aluminum foil and stored at $4^{\circ} \mathrm{C}$ in refrigerator till use.

\subsubsection{Aqueous Extraction of Dry Sample}

The dry sample was powdered and then treated with distilled water $(2: 20 \mathrm{w} / \mathrm{v})$ in $100 \mathrm{ml}$ beakers. The solution was stirred with a glass rod and was kept in hot air oven pre heated at $100^{\circ} \mathrm{C}$. After one hour the extract was allowed to soak for 24 hours at room temperature. The mixture was then centrifuged at $2000 \mathrm{rpm}$ for 10 minutes at $4^{0} \mathrm{C}$. The supernatant was filtered through Whatman filter paper no. 1 fixed on a sterile funnel.

\subsubsection{Methanolic Extraction of Fresh Sample}

The cleaned sample was pulverized with sterile motor and pestle. The extraction was done twice with methanol $(2: 20 \mathrm{w} / \mathrm{v})$ and then the extract was sieved through sterile fine mesh to a $50 \mathrm{ml}$ beaker to make $100 \%$ extract. The beaker was covered with aluminum foil and stored at $4^{0} \mathrm{C}$ in refrigerator till use.

\subsubsection{Methanolic Extraction of Dry Sample}

The dry sample was powdered and then treated with methanol $(2: 20 \mathrm{w} / \mathrm{v})$ in $100 \mathrm{ml}$ beakers. The solution was stirred with a glass rod and was kept at room 
temperature for 48 hours. The mixture was then centrifuged at $2000 \mathrm{rpm}$ for 10 minutes at $4^{\circ} \mathrm{C}$. The supernatant was filtered through Whatman filter paper no. 1 fixed on a sterile funnel

\subsubsection{Preparation of Bacterial Cultures}

\subsubsection{Sterilization of Glass Wares}

Sterilization is an inevitable step in microbiological studies. The required number of petri plates, measuring jar, beaker, conical flask, glass rod and other glassware were first washed with detergent, and rinsed with distilled water. They were then kept in an oven to dry. The glassware and the media were sterilized in an autoclave at $121^{\circ} \mathrm{C}$ and $15 \mathrm{lbs}$ for 20 minutes. Filter paper discs of diameter $4 \mathrm{~mm}$ were made using a punching machine and these were also autoclaved. The inoculation was done in a laminar air flow chamber.

\subsubsection{Bacterial Culture Medium}

The culture media used for liquid and solid culture of bacteria was Nutrient Broth Medium as given in Table 1.

\subsubsection{Preparation of the Medium}

Dissolved 1.3g of Nutrient broth medium (HiMedia, India) in $100 \mathrm{ml}$ of distilled water. The medium was mixed well, autoclaved at $15 \mathrm{lbs}$ pressure for 15 minutes and cooled to $50-55^{\circ} \mathrm{C}$. When used as solid agar medium, $2 \%$ agar $(\mathrm{w} / \mathrm{v})$ was added to the medium before autoclaving.

\subsubsection{Preparation of Inoculum}

A loopful of the permanent cultures of bacterial test strains were inoculated into $5 \mathrm{ml}$ of nutrient broth medium, mixed thoroughly and incubated at $37^{\circ} \mathrm{c}$ for 18 -24 hours.

\subsubsection{Preparation of Agar Plates}

Nutrient broth with $2 \%$ agar medium was prepared and autoclaved in a $500 \mathrm{ml}$ conical flask. $20 \mathrm{ml}$ of the nutrient broth agar medium was poured into each of the

Table 1. Composition of culture medium

\begin{tabular}{|l|c|}
\hline Constituents of culture medium & Optimum characteristics \\
\hline Peptic digest of animal tissue & $0.5 \%(\mathrm{w} / \mathrm{v})$ \\
Sodium chloride & $0.5 \%(\mathrm{w} / \mathrm{v})$ \\
Beef extract & $0.15 \%(\mathrm{w} / \mathrm{v})$ \\
Yeast extract & $0.15 \%(\mathrm{w} / \mathrm{v})$ \\
$\mathrm{pH}\left(25^{\circ} \mathrm{C}\right)$ & $7.4 \pm 0.2$ \\
\hline
\end{tabular}

sterile petri plates. The plates were kept under UV light in a laminar air flow until the medium solidified. The plates were then kept in an incubator for 8 hours and confirmed to be free of contamination.

\subsubsection{Inoculation of the Plates and Antibacterial Activity Analysis}

Inoculation of the plates was done by the disc diffusion method [4]. Filter paper discs were prepared by using punching machine and sterilized in an autoclave.

For antibacterial assay, $100 \mu \mathrm{l}$ of the bacterial cultures were inoculated on to the entire surface of the NB agar plate with a sterile cotton swab to result in a uniform bacterial lawn. The sterile paper discs ( $4 \mathrm{~mm}$ in diameter) impregnated with the plant extracts were placed on the surface of each nutrient broth agar plate using a sterile pair of forceps.

Control plates were also inoculated with paper discs impregnated with the solvent, methanol. The plates were incubated at $37^{\circ} \mathrm{C}$ for $18-24$ hours. All the experiments were conducted in triplicates.

The diameter of the zone of inhibition, if any, was measured using a ruler and noted appropriately. The results were assigned to three categories depending on the diameter of the zone of inhibition as high sensitivity $(\geq 17 \mathrm{~mm})$, intermediate sensitivity $(14-17 \mathrm{~mm})$ and low sensitivity $(<14 \mathrm{~mm})$.

\subsection{Analysis and Interpretation of Data}

The results on the effect of the spice on the growth of pathogenic and probiotic bacteria were obtained by conducting experimental analysis using disc diffusion method. The diameter of zone of inhibition exhibited by the extract was measured using ruler. The obtained results were then tabulated separately. The values were then interpreted as high sensitivity $(\geq 17 \mathrm{~mm})$, intermediate sensitivity $(14-17 \mathrm{~mm})$, low sensitivity $(<14 \mathrm{~mm})$ and resistant. The results were discussed with previous studies, to maintain the relevance and authenticity of the present study.

\section{Results and Discussion}

\subsection{Effect of the Spice on Growth of Pathogenic Bacteria}

Natural antimicrobials are secondary metabolites that can be found in plants. Studies suggest that the 
bio-components of spices have a wide effect on many of the common pathogenic bacteria.

Antibacterial effect of aqueous and methanolic extract of turmeric was studied on four common human pathogenic bacteria including Bacillus cereus, Staphylococcus aureus, Escherichia coli and Salmonella typhimurium. The activity of the spice extract on these bacteria was estimated by disc diffusion method. The area of zone of inhibition was measured to analyze the sensitivity and resistance of the bacteria towards each spice extract. The results were categorized as high sensitivity (zone of inhibition $\geq$ $17 \mathrm{~mm}$ ), intermediate sensitivity (zone of inhibition $14-$ $17 \mathrm{~mm}$ ) and low sensitivity (zone of inhibition $<14 \mathrm{~mm}$ ).

\subsubsection{Antibacterial Activity of Turmeric}

Turmeric is the boiled, dried, cleaned and polished rhizomes of Curcuma longa. Turmeric is used to flavor and to color foodstuffs. Turmeric oleoresin is used in brine pickles and to some extent in mayonnaise and relish formulations, non-alcoholic beverages, gelatins, butter and cheese etc. It is stomachic, carminative, tonic, blood purifier and an antiseptic. The effect of aqueous and methanolic extract of fresh as well as dry sample of turmeric against the selected pathogenic bacteria is shown in the Table 2 and Figure 1.

The gram positive pathogenic bacteria Bacillus cereus showed sensitivity $(11 \mathrm{~mm})$ towards aqueous extract but it was resistant towards methanolic extract of fresh turmeric sample. It also showed resistance towards the dry turmeric extracts.

The gram positive pathogenic bacteria Staphylococcus aureus, showed low sensitivity $(11 \mathrm{~mm})$ towards aqueous extract of fresh turmeric sample but the bacteria was resistant towards the methanolic extract of same

Table 2. Antibacterial activity of turmeric

\begin{tabular}{|l|c|c|c|c|c|}
\hline \multirow{2}{*}{ Sl.No } & \multirow{2}{*}{ Pathogenic Bacteria } & \multicolumn{4}{|c|}{ Zone of inhibition (mm) } \\
\cline { 3 - 6 } & & \multicolumn{2}{|c|}{ Fresh } & \multicolumn{2}{c|}{ Dry } \\
\cline { 3 - 6 } & & Aqueous & Methanol & Aqueous & Methanol \\
\hline 1. & Bacillus cereus & $11 \mathrm{~mm}^{*}$ & - & - & - \\
\hline 2. & Staphylococcus aureus & $11 \mathrm{~mm}^{*}$ & - & - & $9 \mathrm{~mm}^{*}$ \\
\hline 3. & Escherichia coli & $17 \mathrm{~mm}^{* * *}$ & $15 \mathrm{~mm}^{* *}$ & - & - \\
\hline 4. & Salmonella typhimurium & - & - & - & - \\
\hline
\end{tabular}

$\left({ }^{*}\right.$ Low, ${ }^{* *}$ Intermediate, ${ }^{* *}$ High $)$

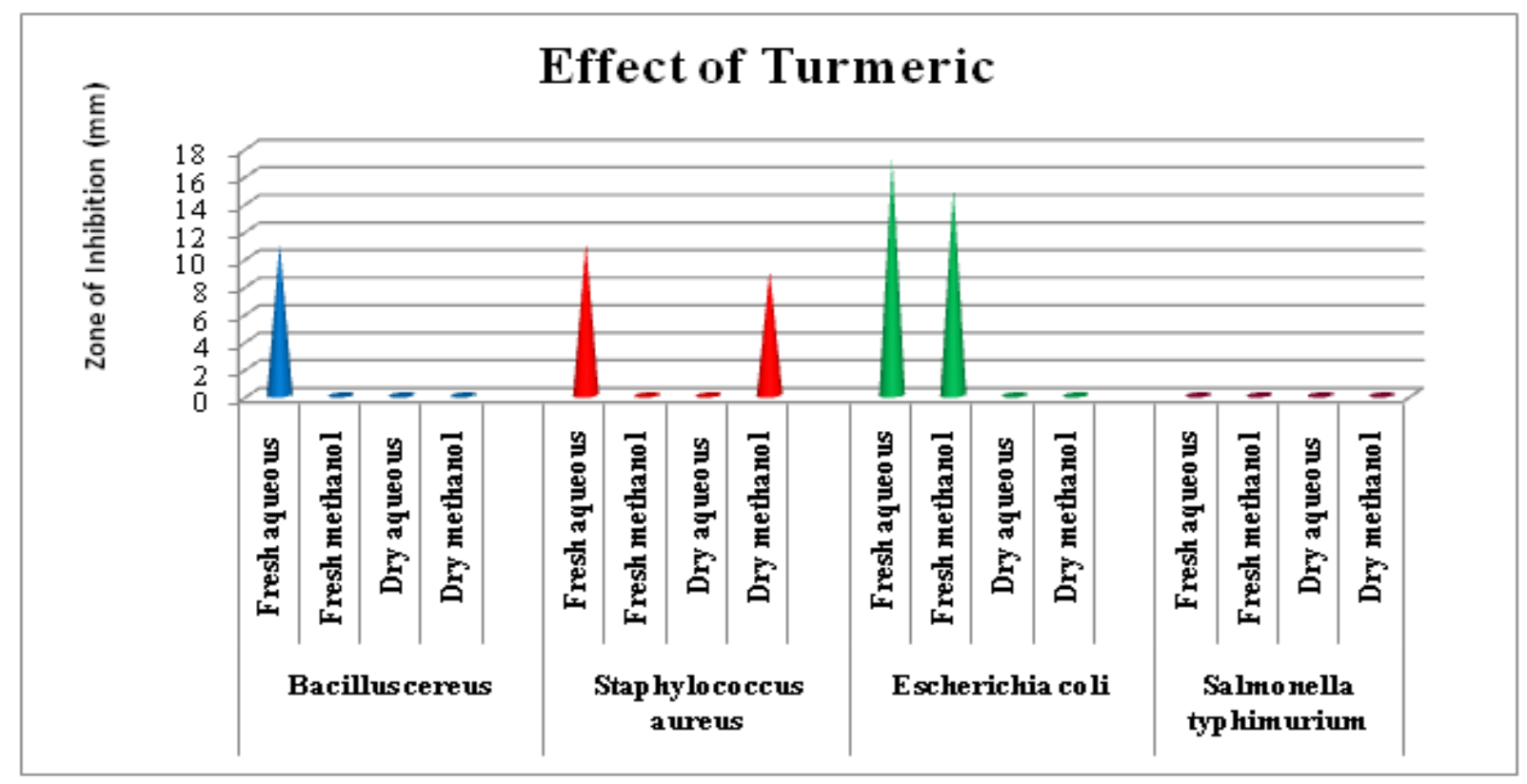

Figure 1. Graphical representation on effect of Turmeric on growth pathogenic bacteria. 
sample. Pundir [5], reported that the fresh aqueous extract of turmeric showed good inhibitory activity against the gram positive Staphylococcus aureus. Manonmani [6], has reported that the methanolic extract of dry Curcuma longa (Turmeric) showed an inhibitory activity against Staphylococcus aureus.

The gram negative pathological bacteria E.coli showed high sensitivity $(17 \mathrm{~mm})$ towards aqueous extract and intermediate sensitivity $(15 \mathrm{~mm})$ towards methanolic extract of the fresh turmeric. Pundir [5] also reported that the widest zones of inhibition by the methanolic extract of fresh turmeric was against E.coli $(11 \mathrm{~mm})$. Whereas the bacteria showed resistance towards aqueous extract as well as methanolic extract of dry turmeric sample.

The gram negative pathogenic bacteria S.typhimurium was resistant towards both fresh and dry samples of turmeric.

Thus from the results obtained from it is clear that the aqueous extract of fresh turmeric showed high inhibitory activity towards the test strains namely Bacillus cereus, Staphylococcus aureus ( than dry methanol extract) and E.coli (than the methanolic extract).

\subsection{Effect of Spice on the Growth of Probiotic Bacteria}

Probiotics have been valued for their potential benefits to overall health. These normal micro floras of the human gut are known to limit the ability of pathogenic bacteria to get attached to the intestinal mucosa. Studies report that the secondary metabolites found in spices have effect on the common pathogenic bacteria but their effect on beneficial probiotic bacteria is not yet being fully explored. The present study is an attempt to analyze the effect of selected spices on the growth of probiotic bacteria in the gut.

The effect of aqueous and methanolic extract turmeric was studied on two gram positive beneficial human probiotic bacteria including lactobacillus and bifidobacterium. The activity of the spice extract on these bacteria was estimated by disc diffusion method. The area of zone of inhibition was measured to analyze the sensitivity and resistance of the bacteria towards each spice extract. The results were categorized as high sensitivity (zone of inhibition $\geq 17 \mathrm{~mm}$ ), intermediate sensitivity (zone of inhibition $14-17 \mathrm{~mm}$ ) and low sensitivity (zone of inhibition $<14 \mathrm{~mm}$ ) and no zone of inhibition as resistant. It is interpreted that, if the probiotic bacteria show resistance towards a spice extract it can be considered beneficial.

\subsubsection{Effect of Turmeric on Probiotic Bacteria}

Turmeric is being identified with preventive action against arthritis, heartburn, stomach pain, diarrhea, intestinal gas, stomach bloating and loss of appetite, jaundice, liver problems and gallbladder disorders. The Table 3 and Figure 2 shows the sensitivity of two gram positive beneficial probiotic bacteria of the gut towards turmeric extracts.

The gram positive probiotic beneficial lactobacillus and bifidobacterial strains were resistant towards the aqueous and methanolic extract of fresh and dry extract of turmeric.

Thus from the results obtained from it is clear that turmeric is helpful in protecting the health of human gut since it doesn't possess any antibacterial activity against the beneficial probiotic strains.

\section{Conclusion}

The study concluded that the spice exhibit wide range of antibacterial activity against the most of the common pathogenic bacteria including Bacillus cereus, Staphylococcus aureus, Escherichia coli. The most important finding of the study is that the same sample of spice does not inhibit the growth of lactobacillus and bifidobacterium, the two beneficial probiotic bacteria which are required to maintain a healthy gut in the human body.

It is also clear that the fresh sample of spice possess higher range of antibacterial activity towards the pathogenic bacteria than the dry spices. The low range of antibacterial activity shown by the dry spices may be due to the loss of essential phytochemicals during processing.

Table 3. Effect of Turmeric on probiotic bacteria

\begin{tabular}{|l|c|c|c|c|c|}
\hline \multirow{2}{*}{ Sl.No } & \multirow{2}{*}{ Probiotic Bacteria } & \multicolumn{3}{|c|}{ Zone of inhibition (mm) } \\
\cline { 3 - 6 } & & \multicolumn{2}{|c|}{ Fresh } & \multicolumn{2}{c|}{ Dry } \\
\cline { 3 - 6 } & & Aqueous & Methanol & Aqueous & Methanol \\
\hline 1. & Lactobacillus & - & - & - & - \\
\hline 2. & Bifidobacterium & - & - & - & - \\
\hline
\end{tabular}




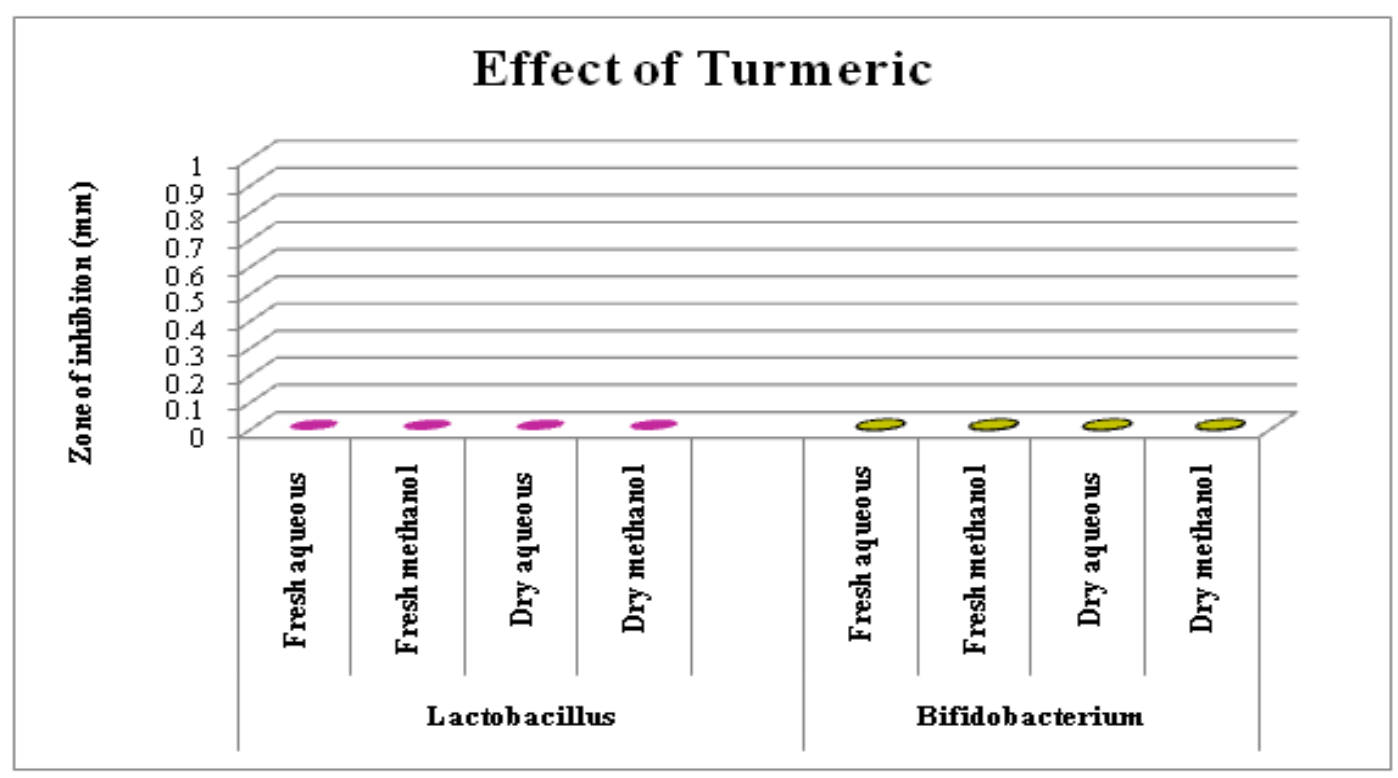

Figure 2. Graphical representation on effect of Turmeric on growth of probiotic bacteria.

Thus the use of fresh spices in the culinary preparations will be beneficial to prevent most of the food borne illnesses.

\section{References}

1. Holt P. R., et al., "Curcumin therapy in inflammatory bowel disease: a pilot study", Digestive Diseases and Sciences, vol. 50(11), p. 2191-2193, 2005.

2. Srinivas L., et al., "Turmerin: a water soluble antioxidant peptide from turmeric [Curcuma longa]", Archives of biochemistry and biophysics, vol. 292(2), p. 617-623, 1992.

3. Gurib-Fakim A., "Medicinal plants: Traditions of yesterday and drugs of tomorrow", Journal of Molecular Aspects of Medicine, vol. 27, p. 1-93, 2006.
4. Baeur A. W., Kirby W. M., Sherris J. C., and Turck M., "Antibiotic susceptibility testing by a standardized single disc method", Am J Clin Pathol, vol. 45(4), p. 493-496, 1966.

5. Kumar P. R., and Pranay J., "Comparative Studies on the Antimicrobial Activity of Black Pepper (Piper Nigrum) and Turmeric (Curcuma Longa) Extracts", International Journal of Applied Biology and Pharmaceutical Technology, vol. 1(2), p. 491-501, 2010.

6. Manonmani P., et al., "Synthesis of Silver Nanoparticles Using Natural Products From Acalypha Indica (Kuppaimeni) And Curcuma Longa (Turmeric) On Antimicrobial Activities", International Journal of Pharmaceutical Research and Bio-Science, vol. 4(1), p. 151-164, 2015. 